\title{
Ubiquitous Mobility with Mobile Phones: a cultural ecology for mobile learning
}

\author{
JOHN COOK \\ London Metropolitan University, United Kingdom \\ NORBERT PACHLER \\ Institute of Education, London, United Kingdom \\ BEN BACHMAIR \\ University of Kassel, Germany
}

\begin{abstract}
This article argues that mobile phones should be viewed as new cultural resources that operate within an individualized, mobile and convergent mass communication; such a recognition facilitates the options for a cultural ecology. A particular challenge here is to find adequate curricular functions in school where the inclusion of these new cultural resources can and should be introduced. The authors expand their argument, first, by discussing mobile devices as cultural resources theoretically from the perspective of their position within what they call a triangular-oriented mobile complex; second, by means of this triangular analysis of structures, agency and cultural practices the mobile complex is investigated with the purpose of positioning the school in relation to this complex; third, they present the notion of user-generated contexts as a means of integrating meaning-making from the world outside of schools into the school and its curriculum. User-generated context is conceived by the authors in a way in which users of mobile digital devices are being 'afforded' synergies of knowledge distributed across people, communities, locations, time (life course), social contexts and sites of practice (such as socio-cultural milieus) and structures. In order to concretize this notion of context they give a brief example. The article then goes on to draw on a case study of a school project that examines mobile devices and associated media within school mathematics. This analysis leads the authors to propose some guidelines for mobile learning. They conclude by noting some significant methodological challenges for their future research around the mobile complex and user-generated contexts.
\end{abstract}

\section{Introduction}

This article examines the school and classroom as part of a cultural media ecology. It does so within the context of a changing world outside schools and with particular reference to the evergrowing ubiquity of mobile phones. We take this stance because we believe that schools are on the one hand a moulding feature of social and individual life; on the other, they are undergoing a transformation as a result of the changes in the world at large towards individualisation, mobility and convergence. Media in its widest sense forms an ecology of cultural resources that we inhabit and that shapes our meaning-making - both what we know and how we come to know it. Specifically, we suggest that it is not sufficient to just add mobile phones to the long list of media which migrated from mass communication into schools with the aim of enhancing tuition. Instead, we argue that mobile phones should be viewed as new cultural resources that operate within an individualized, mobile and convergent mass communication. Recognizing mobile devices as cultural resources facilitates the options for a cultural ecology which in turn results in and facilitates interference with and interaction between school and mobile mass media. We further argue that 
the attempts to identify mobile devices as cultural resources for learning open up the educational field for an epistemological debate about the ecological nature of resources and meaning-making in and across everyday life and school. A particular challenge here is to find adequate curricular functions in school where the inclusion of these new cultural resources can and should be introduced.

In this article we expand our arguments as follows: first, we discuss mobile devices as cultural resources theoretically from the perspective of their position within what we call the mobile complex -a triangular socio-cultural ecology of social structures that relate to users' agency and to cultural practices of media use and learning; second, by means of this triangular analysis of structures, agency and cultural practices, the mobile complex is investigated with the purpose of positioning the school in relation to this complex which includes meaning-making in everyday life and within schools; third, we present the notion of user-generated contexts as a means of integrating meaningmaking from the world outside of schools (or learning in informal contexts) into the school and its curriculum. In order to reify our arguments, and because at present there exists only a relatively small body of research in this area due to its relative newness, by necessity we draw on examples from outside school education. We further provide a detailed examination of our three-pronged argument by drawing on a case study of a school project that examines mobile devices and associated media within school mathematics. The purpose of this case study is to reveal the options that user-generated contexts afford when it comes to integrating learning in informal contexts into the school. This analysis leads to some guidelines for mobile learning.

\section{Mobile Devices as Cultural Resources}

Worldwide there exists a trend to individualisation fostered by mobility and media convergence which is embodied in mobile phones and other mobile devices and their migration into everyday life. Ubiquity of mobile applications is one result of this trend. Furthermore, the Internet is increasingly dependent on mobiles as the dominant interface for users. In this process, ubiquitous mobility is more than the physical domain of cars and streets; instead, it belongs to Web 2.0 and associated social software. However, one sphere has tended to remain unaffected by this trend towards ubiquitous devices: schools with their formal, institutionalized learning. This state of affairs raises some important questions: are schools right to resist the 'mobile flood'? Or should the school follow the trend of everyday life and respond to the worldwide marketing activities of the mobile economy? Should schools open their doors to the new, miniaturized multimedia computers? These rhetorical questions ask for a profound theoretical pedagogic response and debate. We are trying to find answers within a cultural ecology by considering mobiles as cultural resources, as resources for learning and as a mode of meaning-making. In order to integrate mobile phones and other mobile devices into school instruction and learning, arguments are required that move beyond the simple enhancement and augmentation of learning and teaching by mobile media. Is it appropriate to take an extreme position at one end of the continuum and ban mobiles from the school? Are there convincing arguments for schools worldwide to maintain a position of culturally conservative resistance? We take the view that even the most stabile institution is struggling to protect its practices of teaching against change. Therefore, we wish to raise the following question: are there good educational and instructional reasons for banning mobiles within the context of a wave of cultural transformation outside school?

One relevant argument for schools' objection to mobile devices is rooted in the entanglement of mobiles with the worldwide culture of entertainment and banal mass communication, with its superficial modes of communication such as SMS and persistent telephone small talk. Other serious arguments refer to new forms of bullying among young people. To some extent it is a legitimate consideration to use the school as a protection against distraction from the necessary habitus and attitudes for serious and successful learning. It is obvious that mobiles are the interface to the Internet within new mass communication systems which destabilize established school-based modes of learning. A key notion capturing this development is provisionality (see Kress, 2010, p. 171), with learning being subdued by provisionality; it is

[a] condition in which crucial characteristics of the environments of communication may vary

from one moment to the next.... Its effects emerge in the corrosion, fraying, dissolution, 
destruction, abandonment, of older social relations, forms, structures, 'givens'. That has generated far-reaching changes in all domains of meaning: in 'semiotic production' - in the shift from the technologies of print to digital means; in the dissemination of messages - markedly in the shift from the print media to the media of the screen, as much as in the move from the ('traditional') mass-media to the new sites of 'multiplicities of dissemination'; and in representation - in the shift from the dominance of the mode of writing to an insistent use of many modes. (Kress, 2010, p. 171)

We see new mobile mass communication as increasingly impacting upon traditional learning of the school in this process of ongoing cultural transformation.

The following questions are, however, pertinent: is the dawn of what we term 'new mobile mass communication' necessarily a negative development? What about the user-generated contexts (Cook, 2007; Cook, 2010a; Pachler, Bachmair \& Cook, 2010; Pachler, Cook \& Bachmair, 2010) fostered by Web 2.0 and their potential supportive function for situated learning (see Lave $\&$ Wenger, 1991)? Is teacher-guided instruction the perfect context for learning in all situations? The increase of informal learning suggests that we take other contexts into serious consideration for learning. This is particularly true for new and user-generated contexts which reside at the interface of mobiles, everyday life, the Internet and school. Surely they are worth discussing in the context of pedagogy? User-generated contexts within mass communication challenge pedagogy to look beyond the existing standardized, stabile contexts of school learning. Therefore, we propose to apply the educational ideas of situated learning (Lave \& Wenger, 1991) to dealing with usergenerated contexts in schools. We will discuss some examples of user-generated contexts by means of mobile devices later in this article. In the rest of this section we provide some general examples of social networking that are widely available on mobiles to motivate our discussion.

Mass media are witnessing a paradigm shift in which the 'user' can generate their own content with a mobile phone or another digital device - for example, in the form of pictures or video clips; they can then go on to publish them almost immediately on the Internet via media platforms such as Flickr (for annotated photographs), Twitter (for microblogging or 'diary-like' social messages that are no longer than 140 characters), Facebook (a social networking site) or YouTube (for video clips and comments). For example, YouTube is not a traditional form of mass communication; essentially, it is made up by a lot of individuals publishing user-generated content (in the form of videos that users have produced themselves or digital media that have been copied from some other source, the latter may be subject to copyright restrictions). Consequently, we suggest that what we are seeing is the emergence of 'user-generated contexts'. Not only do the twenty-first-century structures of mass communication provide a wide range of augmentations to communication but in addition, through the agency of users, the context within which communication takes place is augmented by users to suit the needs of the individual and/or the conversational community; this we consider to be an important aspect of the mobile complex.

\section{The Mobile Complex, the Socio-cultural Ecology and Schools' Options for Responding Educationally}

We propose that it is essential to take into account the emergence of 'new mobile mass communication' as an educational challenge which should be theoretically considered within a wider referential frame. We see 'new mobile mass communication' as part of what we are calling a mobile complex. By 'wider' we mean looking beyond the isolated technical device and discussing the ongoing social, cultural and technological transformation. We understand the mobile phone and other mobile devices to represent the visible tip of the iceberg of a technological and cultural transformation, what we here call the mobile complex. There is a mobile complex of which, among others, forms of mobile, individualized and convergent mass communication are characteristic. In relation to the mobile complex, schools have a cultural responsibility. This responsibility requires a critical, theoretical frame to balance the deteriorating cultural transformation driven by the context of the mobile complex with the learning options of new cultural resources.

The above statement on the mobile complex and its function in framing cultural resources presents one of the key ideas of the London Mobile Learning Group of which we are members 
(http:/ / www.londonmobilelearning.net; Pachler, Bachmair \& Cook, 2010). For us, the notion of cultural resource is, metaphorically speaking, the conceptual anchor in the sea of ongoing cultural transformation. Indeed, for us, the following is obvious and cannot be neglected: mobile devices do serve as communicative, conversational [1] resources in everyday life - for example, they are used for small talk/chat, to access archives of photos, for the organization of time with the help of the alarm clock and calendar functions, and to access conversational social networks on the Internet (e.g. Twitter). Another key concept for us is that when mobile devices act as communicative and conversational cultural resources, attendant educational tasks receive an ecological frame. We are not solely concerned with the interrelation of new digital media with literacy and media competency in our educational analysis - for example, with how to avoid bullying through the use of mobile phones. Instead, we concentrate on the communicative, conversational capacity of mobile applications as a resource for formal learning in the school. Therefore, we conclude that it is imperative that we consider the cultural resources that are available to enable participation in our changing culture in a global world which is driven by an expanding economy. Pachler (2010) and Pachler, Bachmair \& Cook (2010, pp. 155ff.) describe our approach to a cultural ecology for mobile learning in more detail. Mobile devices are resources that are available worldwide in everyday life for communication, reflection, conversation, informal learning and entertainment, or for consumption. From an ecological perspective, literacy has to be considered not just as a capacity, but also as a cultural resource within conversational practices. By adopting this line of argumentation, we widen the trajectory of the concept of cultural resources. Specifically, beside media and literacy, we also have learning in formal and informal contexts at our disposal as cultural resources. Of course, this furthermore includes the new 'texts' or representational means of mobile devices such as SMS or digital images/video, plus the representational means of Web 2.0, such as YouTube; they all serve as cultural resources.

Considering mobiles among other resources as cultural resources, in this section we pick up on the discussion of the 1970s and 1980s on nature and energy as resources. Nature and energy were seen within the context of fair use in a delicate and unstable biological, social and economic system. What corresponds today to the 'old' resources in a biological, social and economic system? We see a system of individualization, mobility, media convergence and provisionality in which mobile devices, among other things, act as communicative, conversational resources. In the context of an emerging global knowledge society, mobile devices can function as a cultural resource and, as such, need to be critically discussed as resources in a similar way to nature and energy. Indeed, we propose that in such a political view of an analytical investigation of cultural resources, mobile devices have to be considered from the perspective of a triangular argumentation of structures, agency and practices. Consequently, we frame the functioning of mobile devices and learning within a changing socio-cultural environment (structures). Furthermore, we have to consider the interrelation of mobile devices and learning with the agency of children and young people in the school and in their life worlds. Indeed, we have to discuss the practices of learning and media use with their specific rationales. For the ongoing social and cultural transformation, we see the characteristics listed below as key, and, for us, they frame mobile devices as cultural resources. Structures, agency and practices are the interrelating feature elements of the mobile complex. The mobile complex constitutes mobile devices and learning as well as literacy as resources. A critical analysis of the interrelated structures, agency and practices, featuring elements of the mobile complex, leads to a socio-cultural ecology of mobile learning which we summarize below; later in the article we discuss some practical proposals for teaching and learning, in the form of culture ecological guidelines for mobile learning.

1. Socio-cultural structures, including digital tools and media:

- educational institutions no longer define learning and knowledge on their own, and they are certainly no longer the only site, or even the main site, where learning and knowledge can be accessed and take place;

- from push to pull; change of mass communication and media convergence;

- individualized mobile mass communication and social fragmentation into different milieus.

2. Agency as capacity to act on the world:

- formation of identity and subjectivity; 
- the environment as a potential resource for learning;

- different habitus of learning and media attitudes; a new habitus of learning is one of the characteristics of at-risk learners.

3. Cultural practices as routines in situations:

- institutional settings, be they school, university, the work place, etc.;

- media use in everyday life (includes informal/non-formal).

This triangle of structures, agency and practices derives from a widened structuration theory. The original structuration theory was developed by Giddens (1984, pp. 1-40) to describe societal and social development as an interrelationship of pre-given structures and people's agency to deal with their world. This bilateral interplay needs to be widened theoretically by the dominant cultural practices, such as instruction in schools or the use of mass media. Beside this cultural analysis, we widen and adjust the structuration theory to take account of the ongoing cultural transformation. The intention of the London Mobile Learning Group is to contribute to a critical educational theory by emphasizing the concept of cultural resource in relation to mobile devices. As we have already noted, the concept of cultural resource takes up the historico-cultural debate from the 1970 s and 1980s, when the exploitation of energy and of nature was discussed within an ecological approach. In this discussion, the question of participation and equality was of similar importance that is, it revolved around the sustainable and protective use of resources. Learning and individualized mobile, convergent media are recognized as cultural resources. In this perspective, a socio-cultural ecological approach on to learning tries to deal educationally with mobility and learning within a mobile complex. For details of the triangular model, which considers ecologically the interrelation of socio-cultural structures, agency and practices, see Bachmair 2010a, pp. 19ff.; Pachler, Bachmair \& Cook, 2010, pp. 11ff., 155ff., 205ff. Below, we elaborate on how the mobile complex impacts on schools.

Individualized and mobile mass communication is an established feature not only in the everyday life of young people but also in that of children. Mobile phones have a variety of applications and are the visible 'apex' of the mobile complex. To the mobile complex we assign mobile devices as the interface to the Internet, with its social sites and media platforms such as YouTube. What about learning within the mobile complex? Until now the school has maintained the role of the dominant cultural practice of formal learning. But there are also innovative teachers and schools who are investigating the learning potential of mobile devices. There exists a lot of curricular potential for mobile learning (see Mo-LeaP - The Mobile Learning Projects Database, a service provided by the London Mobile Learning Group [LMLG], http://www.moleap.net; Naismith et al, 2004; Kukulska-Hulme \& Traxler, 2005; Sharples, 2007; McFarlane et al, 2008).

In this line of curricular argumentation, a didactic task emerges from learning in informal contexts in everyday life and in mass communication with and around mobiles. Therefore, the educational idea is to integrate learning in informal contexts into the formal learning of the school. Within the frame of cultural resources it would be a misunderstanding for media education to deal with this task only in a technological way. The media education task is not just about adding mobile technology to existing computers, providing flexible Internet access to schools, augmenting whiteboards or replacing still and video cameras with mobile phones for creative media use. In terms of our triangle of socio-cultural development - structures, agency, practices - the relevant educational and didactic task is to assimilate mobile devices into the school's established practices of teaching and learning, by taking into account the following:

- the changing socio-cultural and technological structures, among them individualized mobile mass communication and social fragmentation into different milieus;

- the changing agency of the students; among others, these include the different habitus of learning and different attitudes towards media. The new habitus of learning is one of the characteristics of at-risk learners;

- the mobile and convergent media practices of everyday life.

Figure 1 summarizes the structures, agencies and cultural practices in which mobile phones can be responded to educationally by schools. The left circle of the figure contains the relevant features of the mobile complex within students' everyday life. The emphasis is on individualization in terms of a naïve but native expertise which can be realized within a convergent system of media and the 
Internet. Individualization, naïve and native expertise within media convergence lead to usergenerated contexts and content - for example, on media platforms. The circle on the right depicts the basic options of educational institutions for responding to the mobile complex. The intersection of the two is inhabited by children and young people as learners in informal and formal contexts.

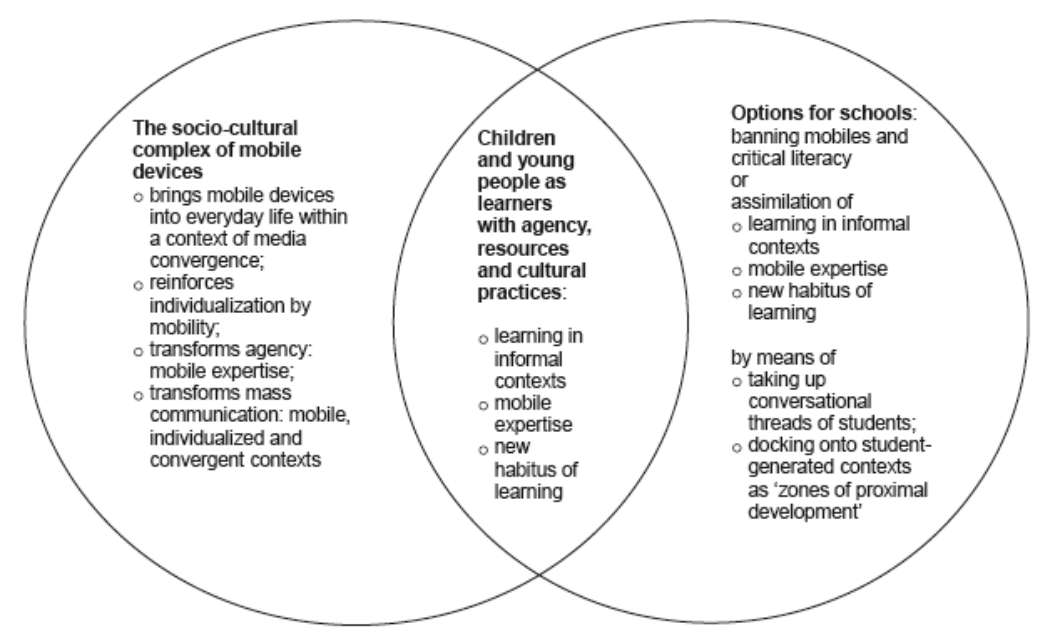

Figure 1. Children and young people as learners at the intersection of the mobile complex and school (Pachler, Bachmair \& Cook, 2010, p. 178).

As part of the mobile complex, mobile devices reinforce individualization and mobility, which has the capacity to transform agency in the context of new, individualized, mobile, convergent mass communication. The key term in the transformation of agency for us is mobile expertise, which relates to a new habitus of learning and correlates with the socio-cultural segmentation of milieus. The key terms in the transformation of mass communication are mobile, individualized and convergent.

\section{User-Generated Contexts}

As we have pointed out already, society is currently witnessing a significant shift away from traditional forms of mass communication and an editorial push towards user-generated content and augmented communication contexts - what Cook (2007) has called user-generated contexts. Above, we also pointed out that through the agency of users, the context within which communication takes place is augmented by users to suit the needs of the individual and/or the conversational community. These ongoing structural transformations are characterized by the following (Bachmair et al, 2009, p. 8):

- a move away from a traditional editorial system towards archives such as media platforms;

- a move away from a push to a pull system of media distribution;

- the use of the mobile phone with a variety of applications as a ubiquitous personal media tool;

- user-generated contents and contexts;

- convergence of the above with Web 2.0 tools for the Internet;

- new structures being developed for the Internet, such as media platforms like YouTube, Flickr and MySpace (these new media platforms are also new forms of archives).

These structural changes to mass communication also affect the agency of the user and their relationship with traditional and new media. For example, the BBC has traditionally acted as being 'in editorial control', commissioning programmes and broadcasting them through a predefined schedule that is transmitted on television. Participants in new mass communications are now actively engaged in generating their own content and contexts for learning. Consider Twitter, which is widely available on mobile phones: by carefully selecting who you follow on Twitter, by judiciously responding to requests, by commenting and by feeding in tweets that are germane, it is 
possible to build a powerful community for professional practice (and of course to build a network for socialization).

Essentially, our argument for a cultural ecology (a macro view) and user-generated contexts (a micro view) draws in particular on the work of Giddens (1984) by proposing that we are witnessing structural changes to mass communication and that these affect the agency, practice and context of users and their relationship with traditional and new media. Although he does not use the term 'context' in the way we envisage, we draw on Giddens' (1984, p. 17) proposition that "social systems, as reproduced social practices, do not have "structures" but rather exhibit "structural properties" and that structure exists ... only in its instantiations in such practices and as memory traces orienting the conduct of knowledgeable human agents'. Structure is, therefore, not simply external to human context and action; a current context is instantiated in practice; is informed by experience, history, and temporal patterns of behavior (see also Cook, 2010b); and manifests itself in the form of structural properties through multimodal interaction with media. As a consequence of these structural changes, the nature of learning is changing as mode of meaning making and users are actively engaged in generating their own content and contexts for learning. We refer to this as user-generated contexts.

Two potential challenges to such a point of view arise, which we address below before attempting a fuller definition of user-generated contexts and providing a concrete example.

The first challenge surrounds the notion of how the word 'context' is to be understood if it is to be seen as 'generated' by the user. Since context generally refers to the interrelated conditions that surround a phenomenon, the question arises as to whether it is in fact counter-intuitive to imagine that all 'context' is generated by the phenomenon in question - in this case, the user. This is not in fact our argument, but is close to what Dourish (2004) proposes. According to Dourish, the determination of context cannot be made a priori but is an emergent feature of 'embodied interaction', determined in the moment and in the activity. In his thinking, 'context isn't something that describes a setting; it's something that people do. It is an achievement, rather than an observation; an outcome, rather than a premise ... [C]ontext cannot be a stable, external description of the setting in which activity arises' (Dourish, 2004, p. 6). Thus, for Dourish, by definition, 'context' exceeds any enumeration or specification, much less any control. We partially agree with Winters \& Price (2005), who argue that Dourish creates an unstable and elusive notion of context which may well hinder any ambition to build interactive systems for context-sensitive learning. Indeed, the case study at the end of this section (and also see Cook, 2010b, for another example) starts from the premise that it is possible to devise an overarching context for users to inhabit at 'run time' and from which to generate their own context for learning. In this sense, we can get a context embedded within a context. Furthermore, towards the end of this article we draw on a case study of a school project that examines mobile devices and associated media within school mathematics and use our resultant analysis to propose some guidelines for user-generated contexts mediated by mobile devices.

The second potential challenge to our line of argument is that we are making a rather strong claim that user generation of contexts is something that has no precedent; it could be argued that we are suggesting that we are witnessing the emergence of 'user-generated contexts' as a new phenomenon. This is not our argument. We readily accept that there have always been some settings where users have a high degree of control and in which they can be said to generate 'context'. For example, situated learning takes place in the same 'context' in which it is applied there is a link between meaning-making and situation/site of practice (Lave $\&$ Wenger, 1991; for a discussion, see Pachler, Bachmair \& Cook, 2010, p. 169). However, we suggest that it may well be the case that previously these digital contexts were highly artificial (e.g. virtual reality, simulations). Therefore, we argue that with mobile devices and their affordances, users are able to generate or control more aspects of 'authentic' or 'real-world' location-based environments or contexts. Users' agency is clearly enhanced by the smart phone.

On the basis of the above, we attempt a more nuanced definition of user-generated contexts: user-generated context for us is conceived in such a way that users of mobile digital devices are being 'afforded' synergies of knowledge distributed across people, communities, locations, time (life course), social contexts, sites of practice (such as socio-cultural milieus) and structures. Of particular significance for us is the way in which mobile digital devices are mediating access to external representations of knowledge in a manner that provides access to cultural resources. This 
dynamic digital-tool mediation of meaning-making allows users to negotiate and construct internal conceptualizations of knowledge and to make social uses of knowledge in and across specific sites or contexts of learning.

In order to concretize the above notion of context, we give a brief example (taken from Smith et al, forthcoming 2011). On the right hand side of Figure 1 we note that in the mobile complex we should be looking at the student-generated contexts as 'zones of proximal development'. By this, we refer to our view that development is a socially negotiated and appropriative process involving the internalization of cultural products. This is what Vygotsky (1978/1930) called a zone of proximal development: 'It is the distance between the actual developmental level as determined by independent problem solving and the level of potential problem solving as determined through problem solving under adult guidance or in collaboration with more capable peers' (p. 86). In order to reify this, we now briefly describe a location-based urban planning tour. As we mentioned in the introduction, in order to support our arguments, and because at the moment there exists only small body of research in this area because it is relatively new, we have found it necessary to draw on an example from outside school education.

Smith et al (forthcoming 2011) present a case study of student teachers' views of a locationaware mobile learning tour, which is designed for users to explore the urban education of a small street area in North London from 1850 to the present day. The context shell for the tour is authored in Mscape and uses GPS to 'push' learning content to the mobile phone at the appropriate location as the user walks around the area. However, the team designed activities that would, it was hoped, allow space for the learners to generate their own context; these activities took the form of active learning tasks and requests for the learners to keep audio blogs for subsequent reflection as they engage in the tour. The evaluation feedback (see Figure 2 for sample participants) shows the value of location-based mobile learning applications and how they can enrich the learning experience as well as engage students more within the learning activity.

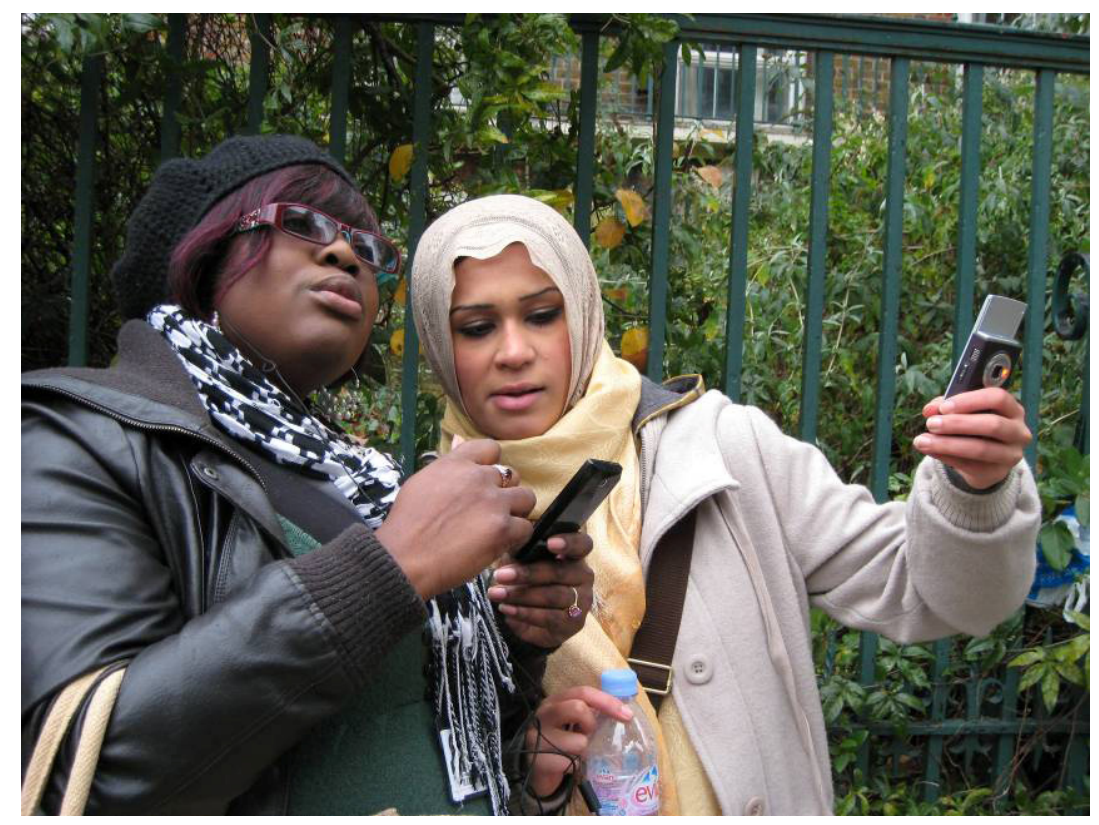

Figure 2. Student teachers taking the mobile tour and recording video blogs (user-generated context).

Specifically, students' attention becomes more focused and they concentrate on the tour more because they are looking out for what is coming up on the device and are motivated to then work on the tasks provided. Students therefore become active learners and are not merely taking in information passively, which they said they would be doing on a traditional tour given by the tutor, where they would be expected to stand and listen to the tutor outside a place of interest. Several students reported that they would be more likely to become distracted or switch off from what the tutor was saying after a while, whereas the mobile tour continued to engage them and held their attention. Another enhancement cited concerned the way the technologies were applied in that the 
content was 'pushed' to them; they didn't have to look for it or read lots of information. Overall, the students said that using the mobile devices made the tour more interesting and engaging and more fun and less boring. There is also a suggestion from one student that the use of the technologies, in particular the GPS technology, provided motivation for increased engagement in the tour (although, on the negative side, the GPS fix did get lost sometimes). However, the following student quote seemed to sum up the very positive results that the research team obtained: "The information given was underlined by the "experience" of the area and, therefore, given context in both past and present.' In this sense, the mobile complex (or, in the case of the above example, a pre-designed context shell) enabled the learners to generate their own context for reflexive learning (in the previous quote, the response is reflective of past and present): they were active participants and not passive recipients in the process as they moved along stages of development in a zone of proximal development.

\section{Report from a German School Project on Mobile Learning}

In this section we present aspects of a German school project on mobile phones with a focus on photo, video and GPS functionality for mathematics in a 6th-grade class with 12-year-old students in order to exemplify the general discussion at the beginning of this article.

The project 'MyMobile: Handy im Unterricht' [2] [Mobile phones within school instruction] was run by the public association 'medien+bildung.com gGmbH'.[3] A maths teacher, together with a media educational professional [4], implemented the instruction unit 'The Mobile between Sphere and Google [Handy zwischen Kugel und Google]: construction and measuring circles and spheres within teacher-guided instruction and episodes of media-orientated student activities'.[5]

From this project we focus on a short mobile video in which a 12 -year-old boy investigates angles at home. He took pictures of different angles and framed them with a German Pokémon song as a soundtrack for his video.
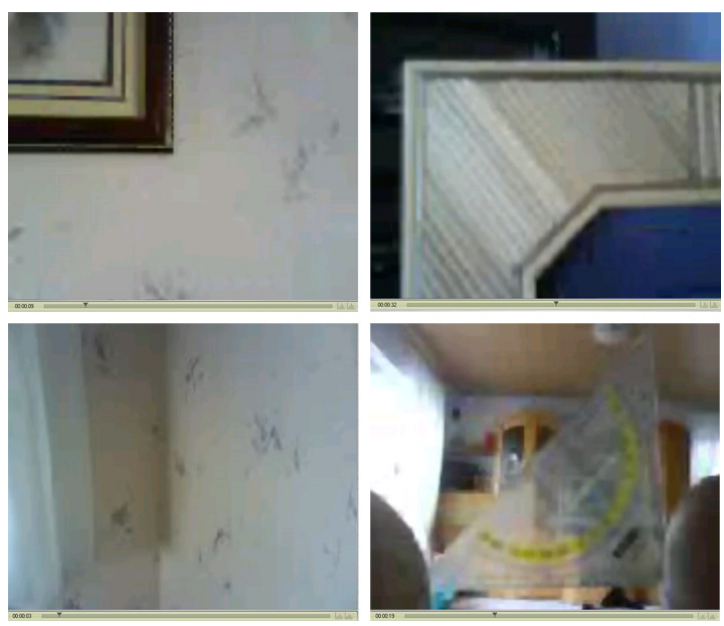

Figure 3. Snapshots of pupil video.

The snapshots of the video in Figure 3 show an interaction between clearness and ambiguity within the boy's physical environment of everyday life. This interaction is a real step to a higher level of reflexivity. This is a remarkable step because everyday life is normally out of bounds for discussions at school; it tends to be taken for granted. In the school the boy's video is not discussed. Therefore, a relevant step to a further level of reflection is missed. Indeed, an informal group discussion of what he had looked for and recorded would have emphasized reflexivity. One must not forget that an increase in reflexivity by way of verbalization is a typical task of the school. The boy reached the first step of reflexivity by attending to the context of everyday life with his mobile phone prompted by a maths task in school. He widened the context of his homework and extended the teaching unit's focus on angles by reflecting on his everyday life at home using his favourite Pokémon song 
as a soundtrack for the video. Furthermore, at the end of his video he refers to Pokémon by showing a picture of a pop song poster or album cover from his personal media world.

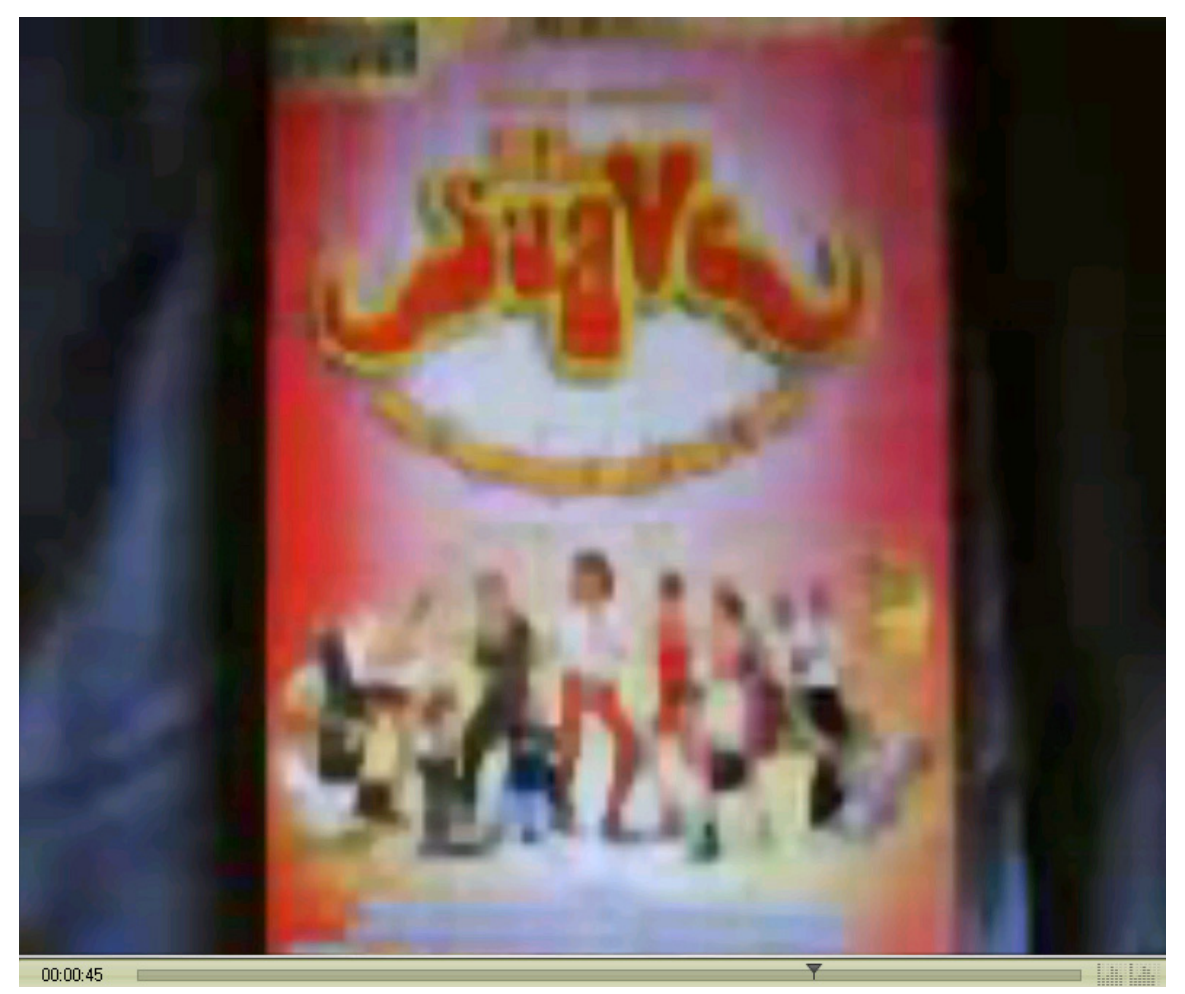

Figure 4. Pop song poster or album cover.

The boy generates a context which combines his maths tuition in school with his media favourites. However, at first glance, and viewed from a perspective outside this personal context, it seems this context does not deal with learning and maths. It may seem that Pokémon is not about maths but is situated in the gender perspective of a boy. Asked by the female media educationist about this, he was not talkative with respect to why he enriched his investigation of angles with a Pokémon soundtrack. We are rather certain that he was not keen to reveal his emotional relation to Pokémon because he relates to Pokémon from a male perspective. For him, and for the majority of boys, Pokémon is related to competition, struggling to get from one level to another. It is about scores and linearly measured development. However, for the male maths teacher, scores and linearity could open a challenging curricular field: how can we bring together (in the context of the teaching of mathematics) the topic of angles as segments of circles and spheres and the entertainment issue of levels and scores? How can we combine the simple linearity of counting and scores with the higher complexity of angles? It is an interesting mathematical task, which has the possibility to be included in the context generated by the boy. The boy generated this context with the help of the applications of the mobile phone and by adding a soundtrack. Furthermore, he took up the linkage between mobile devices and entertainment.

Second, we would like to discuss another example of a media-induced learning context which results from linking the teacher's whiteboard with the student's mobile phone. It is not a technical link via cable or Bluetooth. On the photo in Figure 5 a student engages with the photo application of his/her mobile phone with the teacher's whiteboard. Taken at face value, we see a classroom setting with two media, the whiteboard and the mobile phone. A 12-year-old student takes a photo of the whiteboard on which the teacher drew two circles with the terms Mittelpunkt [centre] and Radius. With this, the teacher introduces the learning unit on angles.

From an analytical point of view, the context is generated by the interaction between the teacher, with his drawing on the whiteboard, and the student, who takes a photo of the two circles. Usually a teacher asks the students to reproduce the circles in their exercise book by means of dividers and handwriting. By using the mobile phone's photo application, the teacher-generated 
context is widened by means of the mobile phone. The video example in Figure 3 makes visible this enlargement of the reflexive learning context. The mobile phone opens the context of the classroom to work at home and to the everyday life of the student. At home the student investigated, among other things, mathematical angles within ambiguity of forms. Specifically, the everyday-life context of the student includes his world of entertainment which contains, among other things, media such as the Pokémon soundtrack. The Pokémon soundtrack is not marginal to his investigation - it is very relevant. It is a strategy game with levels, calculable results, comparisons of success, etc. These issues of the strategy game and the entertainment context are germane to maths.

The teacher's decision to combine the whiteboard with the mobile device offers the option to assimilate two different areas of context. The context of the whiteboard is controlled by the teacher and is based on the structure of teacher-guided instruction. The context of the mobile phone incorporates everyday life and entertainment and belongs to the domain of the students. Both contexts are assimilated into one formal and informal learning context by the teacher + whiteboard and student + mobile phone. The new and widened context contains the formal learning of the school and the informal learning of everyday life, incorporating entertainment.

What is the additional affordance compared with 'just' using homework with an exercise book and dividers? From our perspective, the answer is the integration of the mobile device into everyday life and entertainment. The mobile provides a new context for schools.

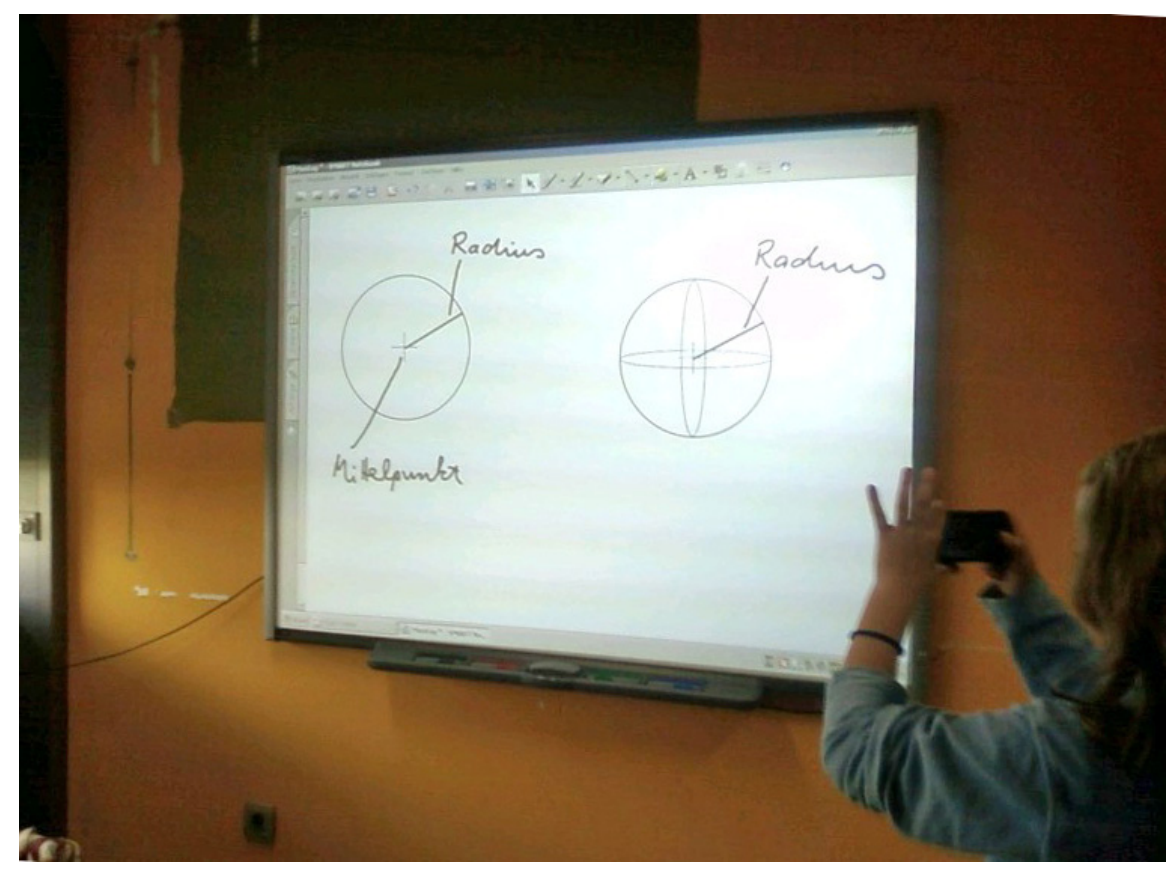

Figure 5. Student taking a photo of the whiteboard.

These two rather arbitrarily chosen examples from maths tuition offer an insight into how media education can deal with the new mobile cultural resources. In the foreground are user-generated contexts which are generated in everyday life with mobile devices and against the background of students' modes of learning and reflexivity in everyday life. Furthermore, from this perspective, the definition of media literacy receives new aspects of reflexivity. It is reflexivity in contexts. Of course, it is a naïve reflexivity which is typical for everyday life. But the school, with its long cultural experiences of reflexivity, could and should concentrate on empowering its students to obtain a higher level of reflection. 


\section{Culture Ecological Guidelines for Mobile Learning}

For practical work in the school and for operationalizing the socio-cultural ecology, we are proposing the following socio-cultural ecological guidelines for mobile learning (see Bachmair 2009, pp. 151ff., 197ff.; 2010b; Pachler, 2010; Pachler, Bachmair \& Cook, 2010, pp. 155ff.):

Mobile phones and other mobile devices function as global cultural resources within a mobile, individualized and convergent mass communication. This dramatically new mode of mass communication includes usergenerated contexts which serve amongst other things as archives for media and knowledge.

Concerns about the development of personality and the learning of children and young people in schools prohibit mobile devices on the school premises and in lessons. The reasons for this include bullying with the mobile phone or access to harmful Internet content by means of mobile phones. Of course, these are educationally relevant issues and tasks for the school to address. Furthermore, the school is concerned with the ubiquitous availability of banal media content and with the proliferation of banal communication which distracts from learning as serious appropriation of relevant curricular content. From this perspective, deliberate educational abstention by schools from mobile phones for learning is legitimate but leads to a need for critical mobile literacy. However, as we have pointed out throughout this article, mobile phones are integral elements of everyday life and the professional world, which suggests to us that schools need to move educationally beyond protection from harmful content and beyond critical media literacy. The normalisation of mobile phones is also given for younger children who live with the mobile phone as a fully accepted family media device. Older children and young people are using mobile applications with the functional breadth of a miniaturized computer, the conversational affordance of telephony and active or passive multimodal media. The normalized and extensive use of mobile applications offers options for learning in schools. Also, the increasing function of the mobile as the ubiquitous interface for media convergence makes it an imminent prospect that the mobile phone will take on the role of dominant access portal for the Internet with its knowledge and media archives.

To summarize, a mobile is a mini-computer which affords mobile access to the individualized and convergent mass communication of media and the Internet. In so doing, the mobile phone becomes a relevant cultural resource within our society and schools should test and integrate mobile applications. Testing and integration of mobile phones within schools should target two endeavours: one is to implement mobile applications as resources for learning; the second is to view mobile devices as resources for participation in society and culture. However, from the perspective of schools, social and cultural participation is mainly based around literacy and formal learning.

Mobile phones and other mobile devices function as resources for learning in formal and informal contexts. An educational task is to use mobile devices for the assimilation of learning of students in everyday life as native and naïve experts.

Individualization in our society supports the development of new and informal modes of learning outside the school and outside of curricula. The PISA results (OECD, 2004, p. 14) make it obvious that schools in general are losing their ability to guide boys from lower social classes and from migrant families to successful learning within the frame of the school (i.e. 'at-risk' learners; see Bachmair et al, 2009). But these students are learning informally with media in everyday life and in the context of entertainment. For these groups of at-risk learners, but also for educationally successful children and young people, the mobile phone carries the option of providing a conversational thread or, in other words, of acting as a conversational bridge from learning in everyday life to curricular and assessed learning in schools. The mobile devices of everyday life afford the option of assimilating a diversity of learning processes by children and young people into those used by the school. Assimilation refers to Jean Piaget's concept of the 1950s (Piaget, 1947/2001, pp. $8,52,110 ; 1955)$. Piaget stressed that the assimilation of the new and unknown into the obvious and familiar offers options for development. In today's individualized mobile network society, children are confronted with new tasks, and options for the development of at-risk learners can and should be devised; these could be supported by the school and by assimilative activities such as conversational threads which link the inside of schools with the world outside. Assimilation 
includes the trends of mass communication and does not cut the school off from these trends. Consequently, we argue for an assimilative curricular approach which uses mobile devices as conversational threads or bridges from the curriculum to the informal learning of everyday life. Teachers can discover and set up such conversational bridging threads if they see and recognize the competences of at-risk learners in everyday life. The key word for this investigation is to discover students as experts in their life-worlds. Students are naïve experts and native experts.

Context-orientated mobile, individualized and convergent mass communication and society pose a challenge for situated learning (Lave \& Wenger, 1991). Situated learning is a way of accessing the essentials of learning which are hidden underneath the established practices of school learning. The focus of the concept of situated learning is based on learning as meaning-making in context. Learning as meaning-making brings into play the life-world of the student. It creates a context that contains the powerful option to replace the passive transfer of knowledge, which is still in the foreground of many schools.

Emerging user-generated contexts and media used in everyday life lead to a new definition of expertise which does not correlate with curricular standards. The new life-world expertise suggests that we need adequate forms of teaching and learning which are remote from traditional instruction. By adopting didactic concepts such as situated learning or collaborative knowledgebuilding, more and more schools are moving away from a simplistic transmission paradigm of instruction. The new paradigm of learning offers a situation in which students are developing the meaning of facts and events. With the help of mobile devices, learning is becoming a form of meaning-making in situations. New convergent mobile and individualized mass communication offers a variety of opportunities for children and young people to make meaning. These situations are closely related to learning. Children and young people, for example, can use the photo or video applications of their mobile phones to take images or shoot films which they upload on Internet platforms. Together, media activities, conversations and Internet sites combine to form contexts. Such contexts can also be set up by mobile videos which are recorded in the school and uploaded onto YouTube's homework community for mathematics, which also provides the possibility for follow-up conversations with peers. By means of a mobile device, a student can open a context not only for his/her activities and for conversations for learning, but also for his/her personal development. Moreover, students are generating their own contexts for activities, conversations, learning and personal development. Schools can link their curricular learning tasks to these usergenerated contexts. It can and should be a didactic task of schools to identify and link such usergenerated contexts of everyday life to schools because they are contexts for development and contexts for learning. The mobile as a multimedia mini-computer supports this because it can deliver the conversational threads between the media-based contexts of everyday life and situations of learning in school.

\section{Conclusion}

We conclude by noting that the social world sets boundaries around the texts, contexts and social relations between users. However, boundaries can be - and are being - contested as new technologies and new cultural practices collide with old ones. One key question that arises for us is this: have we got the structure, agency and cultural practices right? We argue that the triangular relationship in the mobile complex has a powerful explanatory power, and that this macro-level insight is amplified by the fine-grained notion of user-generated contexts. For us, the school-based learning context would benefit from shifting attention in some instances, such as those described above, to the contexts of learning in informal settings in which the native and naïve experts of everyday life are acting in a generative and participative manner. User-generated contexts appear to involve multiple and complex layers of representational activity. As Daniels (2008, pp. 8ff.) notes, such a dialectical view of human meaning-making carries with it significant methodological challenges for research. Our future work will aim to address this challenge for multiple and longitudinal user-generated contexts. 


\section{Acknowledgements}

The conclusions take as a starting point useful comments made by Gemma Moss following the authors' Deutsche Gesellschaft für Erziehungswissenschaften Congress 2010 (Mainz) workshop presentations. Our thanks to the reviewers for their constructive comments.

\section{Notes}

[1] For the concept of conversation for education, teaching and learning see Laurillard, 2002.

[2] http: / / www.medienundbildung.com/index.php?id=464

[3] medien+bildung.com gGmbH - Lernwerkstatt Rheinland-Pfalz - Postfach 2172 63, 67072 Ludwigshafen. http: / / www.medienundbildung.com

[4] Maren Risch, medien+bildung.com gGmbH.

[5] This instructional unit is described at http:/ / www.medienundbildung.com/index.php?id=717; http: / / www.medienundbildung.com/index.php?id=712

\section{References}

Bachmair, B. (2009) Medienwissen für Pädagogen. Medienbildung in riskanten Erlebniswelten. Wiesbaden: VS Verlag für Sozialwissenschaften.

Bachmair, B. (2010a) Einleitung: Medien und Bildung im dramatischen kulturellen Wandel, in B. Bachmair (Ed.) Medienbildung in neuen Kulturräumen. Die deutschsprachige und britische Diskussion, pp. 9-30. Wiesbaden: VS Verlag für Sozialwissenschaften.

Bachmair, B. (Ed.) (2010b) Medienbildung in neuen Kulturräumen. Die deutschsprachige und britische Diskussion. Wiesbaden: VS Verlag für Sozialwissenschaften.

Bachmair, B., Pachler, N. \& Cook, J. (2009) Mobile Phones as Cultural Resources of Learning: an educational analysis of structures, mobile expertise and cultural practices, MedienPädagogik, February. http: / / www.medienpaed.com

Cook, J. (2007) Generating New Learning Contexts: novel forms of reuse and learning on the move. Invited talk, in C. Montgomerie \& J. Seale (Eds) Proceedings of World Conference on Educational Multimedia, Hypermedia and Telecommunications 2007, 2766-2779. Chesapeake, VA: Association for the Advancement of Computing in Education (AACE). See http:/ / bit.ly/bqbltP.

Cook, J. (2010a) Mobile Learner Generated Contexts: research on the internalization of the world of cultural products, in B. Bachmair (Ed.) Medienbildung in neuen Kulturräumen. Die deutschsprachige und britische Diskussion, pp. 113-126. Wiesbaden: VS Verlag für Sozialwissenschaften.

Cook, J. (2010b) Mobile Phones as Mediating Tools within Augmented Contexts for Development, International Journal of Mobile and Blended Learning, 2(3) (July-September), 1-12.

Daniels, H. (2008) Vygotsky and Research. Abingdon: Routledge.

Dourish, P. (2004) What We Talk About When We Talk About Context, Personal and Ubiquitous Computing, 8(1), 19-30. http: / / dx.doi.org/10.1007/ s00779-003-0253-8

Giddens, A. (1984) The Constitution of Society: outline of the theory of structuration, reprint edn., 1986. Berkeley: University of California Press.

Kress, G. (2010) Learning and Environments of Learning in Conditions of Provisionality, in B. Bachmair (Ed.) Medienbildung in neuen Kulturräumen. Die deutschsprachige und britische Diskussion, pp. 171-182. Wiesbaden: VS Verlag für Sozialwissenschaften.

Kukulska-Hulme, A. \& Traxler, J. (Eds) (2005) Mobile Learning: a handbook for educators and trainers, new ed. London \& New York: Routledge.

Laurillard, Diana (2002) Rethinking University Teaching: a framework for the effective use of learning technologies, 2nd ed. London: RoutledgeFalmer. http: / dx.doi.org/10.4324/9780203304846

Lave, J. \& Wenger, E. (1991) Situated Learning: legitimate peripheral participation. Cambridge: Cambridge University Press.

McFarlane, A. Triggs, P. \& Yee, W. (2008) Mobile Learning: research findings. Coventry: Becta.

Naismith, L., Lonsdale, P., Vavoula, G. \& Sharples, M. (2004) Literature Review in Mobile Technologies and Learning. Futurelab Series, Report 11.

http:/ / www.futurelab.org.uk/resources/documents/lit_reviews/Mobile_Review.pdf 
Organisation for Economic Co-operation and Development (OECD) (2004) Messages from PISA 2000. http: / / www.oecd.org/dataoecd/31/19/34107978.pdf

Pachler, N. (2010). The Socio-cultural Ecological Approach to Mobile Learning: an overview, in B. Bachmair (Ed.) Medienbildung in neuen Kulturräumen. Die deutschsprachige und britische Diskussion, pp. 153-167. Wiesbaden VS Verlag für Sozialwissenschaften.

Pachler, N., Bachmair, B. \& Cook, J. (2010) Mobile Learning: structures, agency, practices. New York: Springer. http:/ / www.springerlink.com/ content/v65pt8

Pachler, N., Cook, J. \& Bachmair, B. (2010) Appropriation of Mobile Cultural Resources for Learning, International Journal for Mobile and Blended Learning, 1. http: / / dx.doi.org/10.4018/jmbl.2010010101

Piaget, J. (1947/2001) The Psychology of Intelligence. London \& New York: Routledge Classics. (First published in 1947 as La Psychologie de l'intelligence [Paris: Armand Colin]).

Piaget, J. (1955) The Construction of Reality in the Child. London: Routledge \& Kegan Paul.

Sharples, M. (Ed.) (2007) Big Issues in Mobile Learning. Report of a workshop by the Kaleidoscope Network of Excellence Mobile Learning Initiative. University of Nottingham: Learning Sciences Research Institute (LSRI).

Smith, C., Bradley, C., Cook, J. \& Pratt-Adams, S. (forthcoming 2011) Designing for Active Learning: putting learning into context with mobile devices, in Anders D. Olofsson \& J. Ola Lindberg (Eds) Informed Design of Educational Technologies in Higher Education: enhanced learning and teaching. Hershey, PA: IGI Global.

Vygotsky, L. ([1930] 1978) Mind in Society: the development of higher psychological processes, ed. M. Cole, V. JohnSteiner, S. Scribner \& E. Soubermann. Cambridge, MA: Harvard University Press.

Winters, W. \& Price, P. (2005) Mobile HCI and the Learning Context: an exploration. Context in Mobile HCI Workshop at Mobile HCI05, September, in Salzburg, Austria.

JOHN COOK is Professor of Technology Enhanced Learning at the Learning Technology Research Institute, London Metropolitan University. He has published widely, having a specific interest in four related research areas: informal learning, mobile learning, augmented contexts for development and work-based learning. John is a founding member of the London Mobile Learning Group, was Chair/President of the Association for Learning Technology (2004-6) and is currently the Chair of ALT's Research Committee. Correspondence: Professor John Cook, Learning Technology Research Institute, London Metropolitan University, 35 Kingsland Road, Shoreditch, London E2 8AA, United Kingdom (john.cook@londonmet.ac.uk).

NORBERT PACHLER is Professor of Education and Pro-director: Professional Education Professionals at the Institute of Education, University of London. He is the convenor of the London Mobile Learning Group (http://www.londonmobilelearning.net) and has published widely and researches and supervises in the fields of new technologies in teaching and learning, teacher education and development and foreign language education. Correspondence: n.pachler@ioe.ac.uk

BEN BACHMAIR was until his retirement in 2008 Professor of Pedagogy, Media Education and Instructional Technology at the University of Kassel, Germany. He is a member of the London Mobile Learning Group and visiting professor at the Institute of Education, London. He is a member of the German public regulation board for television and the Internet. His specialisms include: mass communication and education, media and learning, media socialisation and media reception, and media within cultural development, in which he has published widely. Correspondence: bachmair@uni-kassel.de 